Abstracta Iranica Abstracta Iranica

Revue bibliographique pour le domaine irano-aryen

Volume 40-41 | 2019

Comptes rendus des publications de 2017-2018

\title{
Gabrielle van den Berg, Charles Melville (éds.). Shahnama Studies III. The Reception of the Shahnama
}

\section{Viola Allegranzi}

\section{(2) OpenEdition \\ 1 Journals}

\section{Édition électronique}

URL : http://journals.openedition.org/abstractairanica/52067

DOI : 10.4000/abstractairanica.52067

ISBN : 1961-960X

ISSN : 1961-960X

Éditeur :

CNRS (UMR 7528 Mondes iraniens et indiens), Éditions de l'IFRI

Référence électronique

Viola Allegranzi, «Gabrielle van den Berg, Charles Melville (éds.). Shahnama Studies III. The Reception of the Shahnama ", Abstracta Iranica [En ligne], Volume 40-41 | 2019, document 1, mis en ligne le 30 décembre 2019, consulté le 17 avril 2021. URL : http://journals.openedition.org/abstractairanica/ 52067 ; DOI : https://doi.org/10.4000/abstractairanica.52067

Ce document a été généré automatiquement le 17 avril 2021.

Tous droits réservés 


\title{
Gabrielle van den Berg, Charles Melville (éds.). Shahnama Studies III. The Reception of the Shahnama
}

\author{
Viola Allegranzi
}

\section{RÉFÉRENCE}

Gabrielle van den Berg, Charles Melville (éds.). Shahnama Studies III. The Reception of the Shahnama. (Studies in Persian Cultural History 12), Leiden-Boston : Brill, 2018, XIX + 431 p. [ISBN : 978-90-04-35624-5]

1 Ce troisième volume collectif de Shahnama Studies est un ouvrage à caractère multidisciplinaire, qui explore le rayonnement du Šāhnāme de Ferdawsī dans la production artistique et littéraire des mondes iranien, ottoman et indien à travers les époques.

2 La première partie ("The Reception of Shahnama: Later Epics », p. 7-151) se concentre sur des personnages et épisodes « secondaires » du cycle épique persan : Bānū Gušasp, fille de Rustam (M.van Zutphen); Barzū, petit-fils de Rustam (G.van den Berg; K. Yamamoto); l'affrontement entre Rustam et le démon BarHiyās (Ch. Melville). M. Szuppe y présente des nouvelles données sur la tradition manuscrite du Šahriyārnāme.

3 La deuxième partie ("The Shahnama in Later Contexts », p. 153-265) traite de l'emprise du Šāhnāme sur l'art de cour en Iran et dans l'empire ottoman à partir du XV ${ }^{\mathrm{e}}$ siècle. M. Bernardini offre un aperçu des références au poème dans l'historiographie timouride; F.S. Eryılmaz et T. Deǧirmenci présentent des réécritures du Šāhnāme produites à la cour ottomane ; R. Shani analyse le cycle d'illustration d'un Hāâarānnāme, poème qui transpose l'épopée persane en contexte chiite.

4 La troisième section du volume ("Textual Studies », p. 267-313) s'ouvre avec un essai de littérature comparée (C. van Ruymbeke), où les versions de l'histoire de Husraw et Šīrīn 
proposées par Ferdawsī, Neẓāmī et Amīr Hususraw sont mises en parallèle. Suit une analyse anthropologique de la catégorie des filles de rois dans le Šăhnāme (A. Gabbay).

5 La culture matérielle et l'art du livre font l'objet de la quatrième partie (" Art History and Manuscript Studies », p. 315-419). F. Melville présente des nouvelles découvertes et pistes de réflexion sur les références épigraphiques et iconographiques au Šāhnāme sur les carreaux en céramique ilkhanides.

6 L'ouvrage se clôt avec deux études portant sur des manuscrits illustrés : un Šāhnāme produit à la cour de Bijapur, en Inde, vers 1610 (L. Weinstein), ainsi que le moins connu des deux Šāhnāme « de Bāysungiur » complétés à Hérat en 833/1430 (Sh. Mihan).

7 Si plusieurs essais allient l'analyse textuelle et iconographique des œuvres manuscrites, d'autres avancent des réflexions sur l'héritage du Šāhnāme dans la propagande politique et dans la tradition orale des sociétés modernes et contemporaines. L'ouvrage montre ainsi toute l'étendue du thème de la réception du šăhnāme, en proposant une multiplicité de sujets et d'approches.

\section{AUTEURS}

VIOLA ALLEGRANZI

Institut für Iranistik der ÖAW, Wien 